\title{
Design and Implementation of a Planar MIMO Antenna for LTE-Applications
}

\author{
D. Stephy Angel ${ }^{1}$, N.R.Nagarajan ${ }^{2}$, U.Surendar ${ }^{3}$ \\ Assistant Professor, Department of Electronics \&Communication, \\ K. Ramakrishnan College of Engineering Anna University, India ${ }^{1,2,3}$
}

\begin{abstract}
Modern communication systems demand the use of antennas that are light weight, easy to excite and performance over wide range of frequencies. In addition to that, there is a need to implement antennas that have high gain and flexibility. Moreover using two or more antennas to cover various frequency bands will increase the system cost. This leads to the development of MIMO antenna which consists of the micro-strip patch. The main objective of this paper is to design a MIMO antenna which has four radiating elements that are separated by placing $2 \mathrm{~L}$-shaped metallic structures and a Slotted Ground Plane which reduces the correlation coefficient between them. Mutual coupling is reduced by applying the polarization diversity which is achieved by placing the elements orthogonal to each other. Since the gain is more than a single element and gives multiple frequency bands, makes it suitable for LTE applications.
\end{abstract}

Keywords: MIMO; Correlation; Mutual Coupling; Polarization Diversity; SGP; Micro strip; LTE

\section{INTRODUCTION}

MIMO has emerged as a recent technology to achieve very high bandwidth efficiencies and large data rates in wireless communications. The MIMO technology was first studied by Foschini in 1998. The principle is to employ multiple antennas at both the transmitter and the receiver side [1]. The attractive features of MIMO are high performance in wireless communication systems, improved channel capacity, low transmission power, reliable operation in poor signal conditions, high spectral efficiency and high data rates [2]. Researches on MIMO mainly focuses on the communication systems, information theory, signal processing and coding issues. Only little importance is given for antenna designing and their impact on channel capacity, system performance etc. Thus, in this paper the main focus is given for the antenna designing and their significance in the system performance.

In this paper various aspects such as the radiation pattern, gain, directivity, mutual coupling, correlation between the antenna elements are discussed. The antennas used in MIMO should have compact size, low profile, high gain, lower correlation and high isolation[3]. Since the microstrip antennas have some features like small size, lower weight, ease of fabrication, ease of integration with MIC they are more preferable for designing MIMO antenna. Even though the microstrip antennas have many advantages, they have some disadvantages such as low gain, narrow bandwidth, low efficiency, low power handling capacity which limits their use in $3 \mathrm{G}$ and $4 \mathrm{G}$ wireless systems [3]. Bandwidth can be improved by increasing the substrate height or increasing the patch width up to $1 \lambda$. Another method for improving bandwidth is to etch the slots on the antenna which makes the fabrication easy and produces multiple bands. The major issue in MIMO antenna is the mutual coupling between the antenna elements. Mutual coupling is the parameter used to describe the correlation between the elements [4]. High mutual coupling may result in high correlation which in turn reduces the antenna efficiency. The correlation coefficient describes how the radiation patterns of two antennas are independent. Hence the correlation coefficient takes the radiation pattern, polarization and the relative phase of fields of the antenna into account. The correlation coefficient can be reduced by using different polarization and increasing the distance between the antenna elements [5]. This gives rise to the various diversity techniques such as polarization diversity, spatial diversity, multimode diversity and pattern diversity.

In this paper the polarization diversity is used which improves the channel capacity without increasing the distance between the elements. At larger distance, the far field patterns are uncorrelated since the relative phase is not constant. A good MIMO antenna system should have good isolation and the radiation pattern should not be same. Various isolation methods are used in MIMO such as Defected Ground Structure, lumped component structures, Neutralization strips, resonating structures, orientation of antenna and the use of meta materials[6].

The challenges for MIMO antennas are compact and low profile, low mutual coupling, high gain, flexibility, multimode operations, multiple frequency bands, correlation coefficient etc. In this paper various parameters such as the Gain, Directivity, Radiation pattern and return loss are analyzed. 
Vol. 8, Issue 5, May 2019

\section{DESIGN OF SINGLE RADIATING PATCH ANTENNA}

A single radiating element is a rectangular patch designed by printing the patch on the RT-Duroid substrate having the dielectric constant of $\varepsilon_{\mathrm{r}}=2.2$ and a tangent loss of 0.0004 . The substrate height is taken as $1.6 \mathrm{~mm}$, a length of $48.774 \mathrm{~mm}$, a width of $56.47 \mathrm{~mm}$. In order to increase the bandwidth slots are etched on the radiating patch. The rectangular patch is the modified design from [7]. The proposed single radiating patch is shown in figure.1.

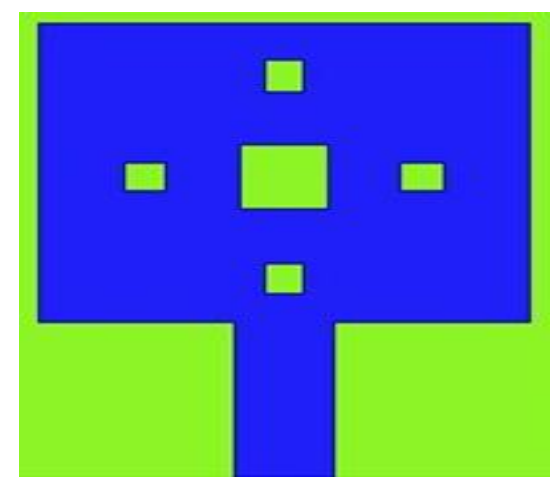

Figure 1 Geometry of single radiating patch

As the slots are etched to increase the bandwidth, it reduces the gain of the antenna. Gain is a measure of antennas efficiency and its directional capabilities. Hence the gain of the single radiating patch reduces from $1.54 \mathrm{~dB}$ to $1.53 \mathrm{~dB}$ which is shown in the figure.2. Directivity of an antenna is defined as the ratio of the radiation intensity in a given direction from the antenna to the radiation intensity averaged over all directions. The directivity of single radiating patch is $1.68 \mathrm{~dB}$ which is shown in the figure. 3 .
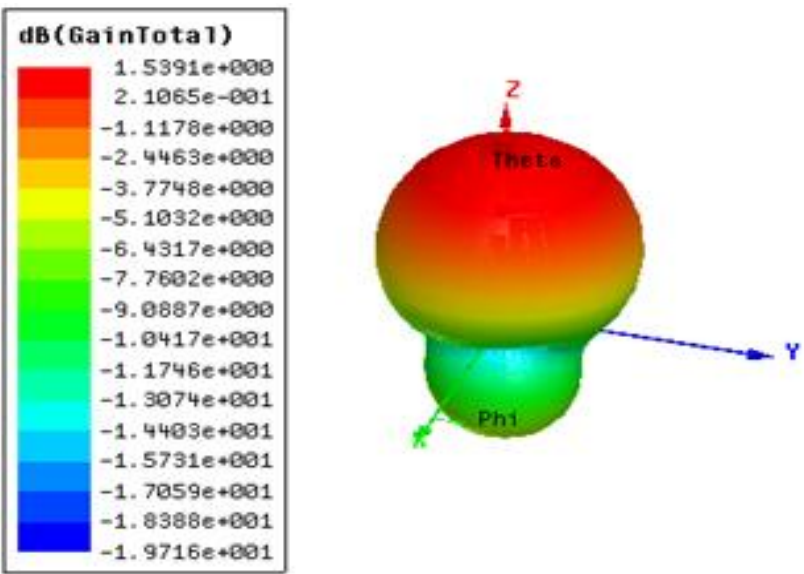

Figure 2 Gain of single radiating patch with slots
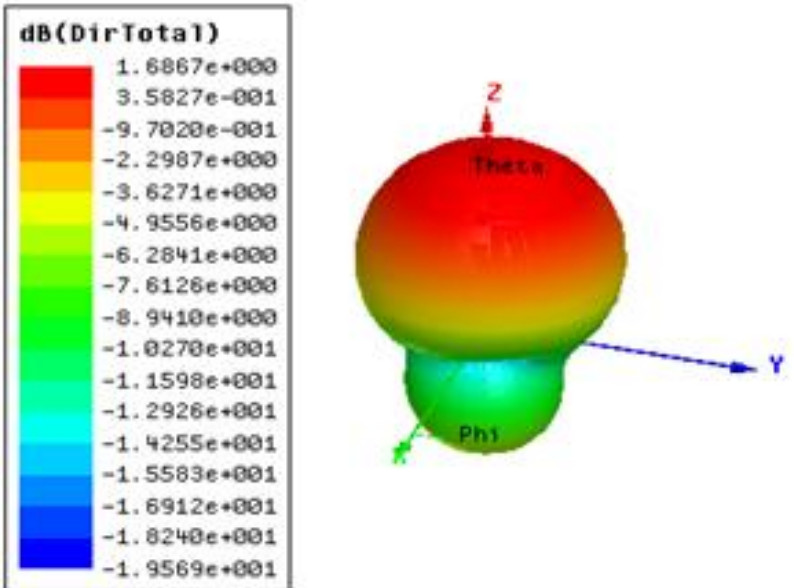

Figure 3 Directivity of single radiating patch 
Vol. 8, Issue 5, May 2019

\section{DESIGN OF TWO RADIATING PATCH MIMO ANTENNA}

The two radiating patch MIMO antenna is designed by placing the elements orthogonal to each other which is the polarization diversity, [8] to reduce the mutual coupling between the two radiating patches. The isolation between the elements are provided by placing the metallic structure between the elements. To provide more isolation the Slotted Ground Plane is used in which the slots are etched on the ground plane. The proposed two radiating patch MIMO antenna is shown in the figure.4. The Slotted Ground Plane is shown in the figure.5.

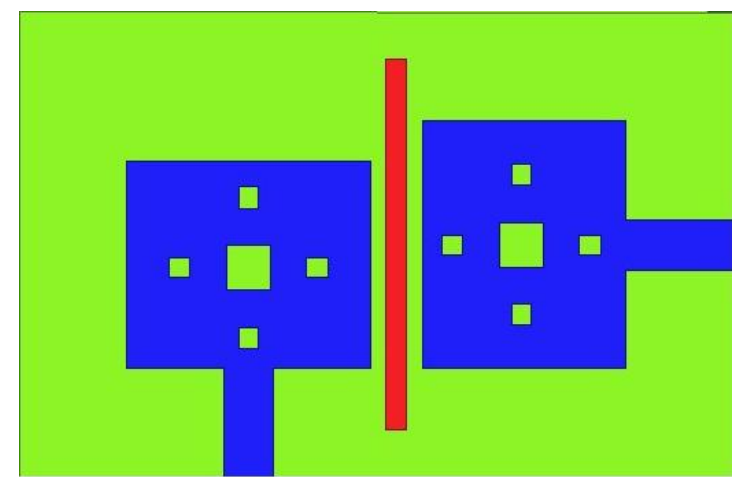

Figure 4 Geometry of two radiating patch MIMO antenna

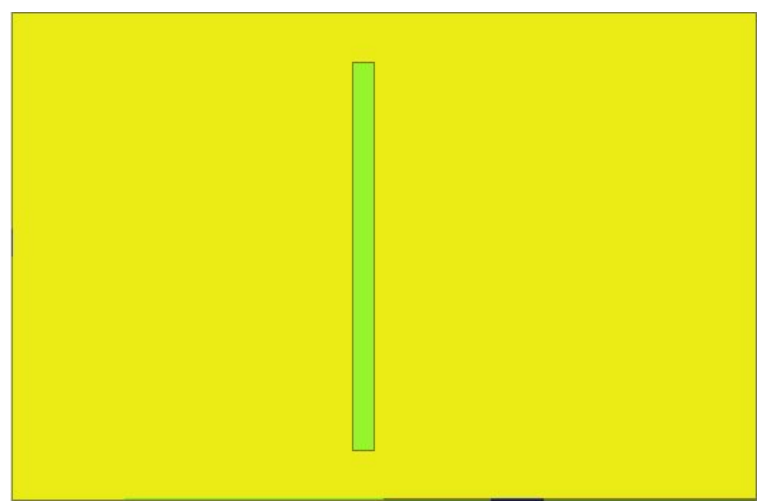

Figure 5 SGP of two radiating patch MIMO antenna

Gain is a measure that takes into account the efficiency of the antenna as well as the antennas directional capabilities. The gain of the two radiating patch MIMO antenna is $2.28 \mathrm{~dB}$ which is shown in the figure.6. The directivity of two radiating patch MIMO antenna is $2.34 \mathrm{~dB}$ which is shown in the figure.7. Return loss indicates the amount of reflection occurring at the same port and is the way of expressing the mismatch. It is a logarithmic ratio measured in $\mathrm{dB}$ that compares the power reflected by the antenna to the power that is fed into the antenna from the transmission line.
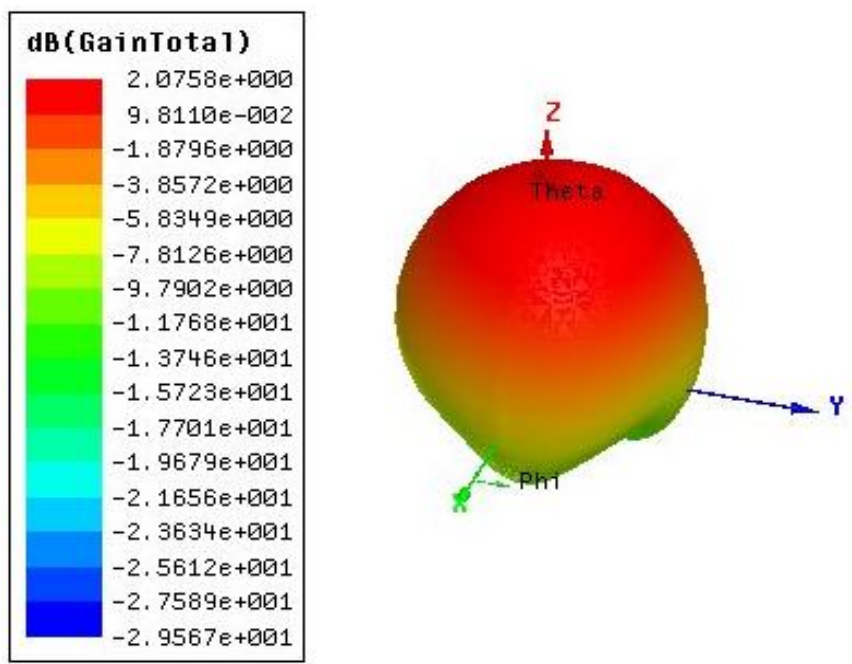

Figure 6 Gain of two radiating patch MIMO antenna 
Vol. 8, Issue 5, May 2019

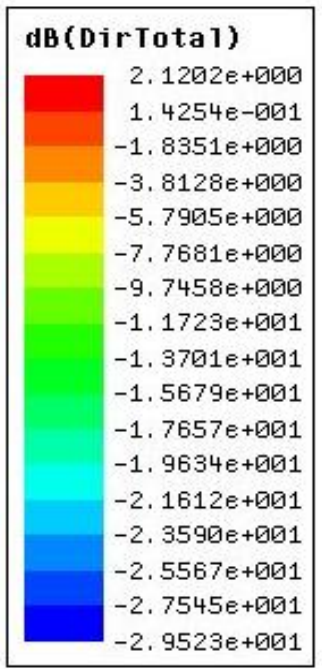

Figure 7 Directivity of two radiating patch MIMO antenna

Since more than one elements are used in MIMO there should be high isolation between the elements. The two radiating patch MIMO has two ports and their return loss are $\mathrm{S}_{11}$ and $\mathrm{S}_{22}$ with $-3.9 \mathrm{~dB}$ and $-4.3 \mathrm{~dB}$ at $2.6 \mathrm{GHz}$ and $12.8 \mathrm{~dB}$ at $4.2 \mathrm{GHz}$ which is shown in the figure. 8 and 9.

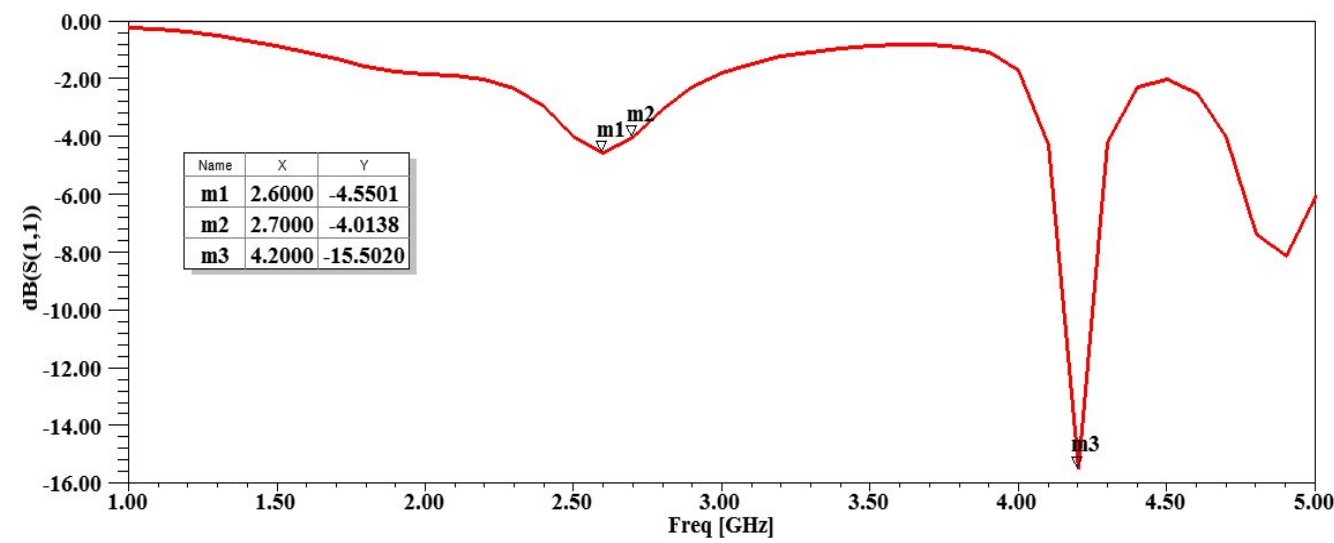

Figure 8 Return loss of two radiating patch MIMO antenna

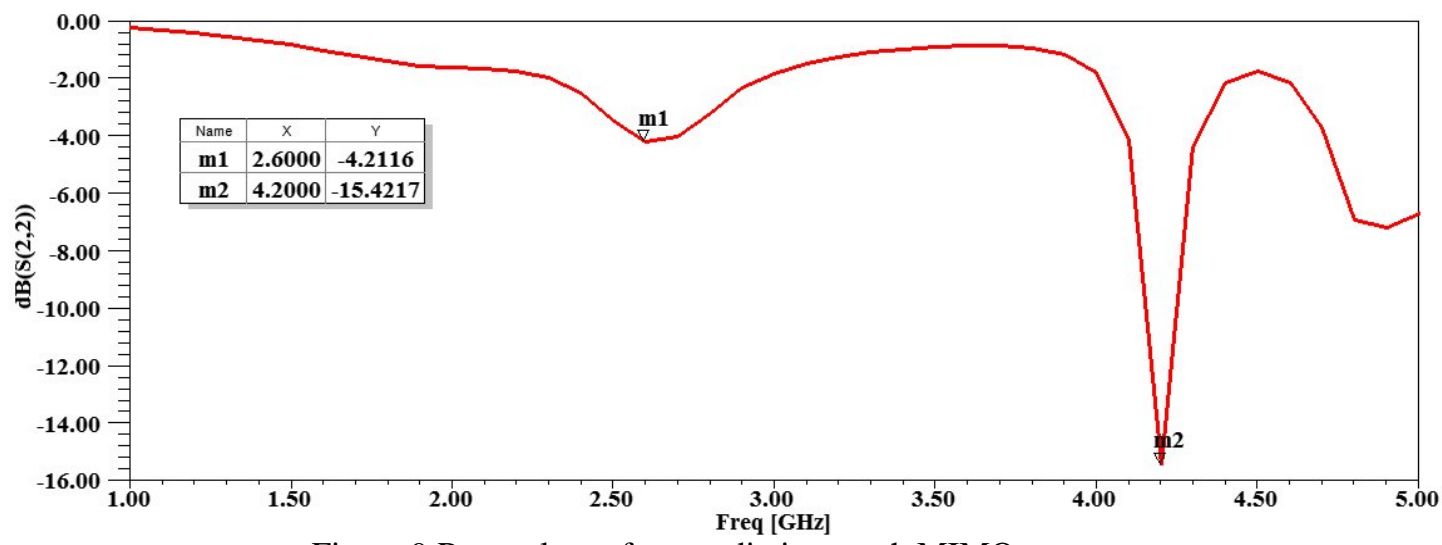

Figure 9 Return loss of two radiating patch MIMO antenna

Radiation pattern is a graphical representation in 2D and 3D of the radiation of antenna as the function of direction. It is a plot of power radiated from an antenna per unit solid angle, which gives the intensity of radiation from the antenna [9]. The 2D radiation pattern is shown in figure. 10.

It is observed that the 2D radiation pattern of two radiating patch MIMO antenna has one small back lobe and no side lobes. The 3D radiation pattern is shown in figure. 11. 
Vol. 8, Issue 5, May 2019

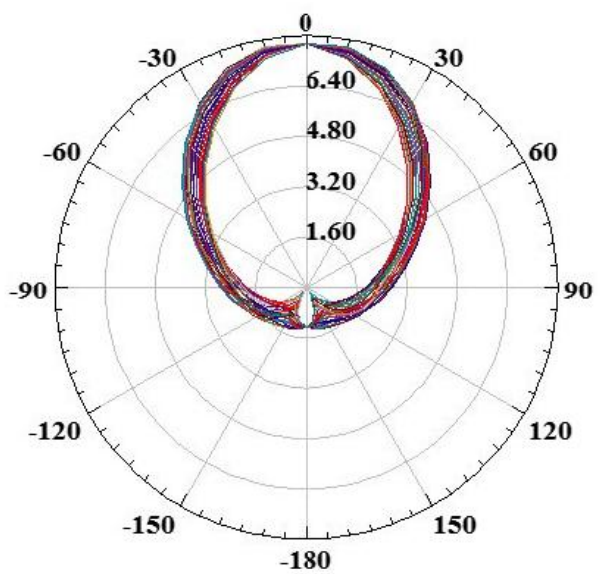

Figure 10 2D Radiation pattern of two radiating patch MIMO antenna
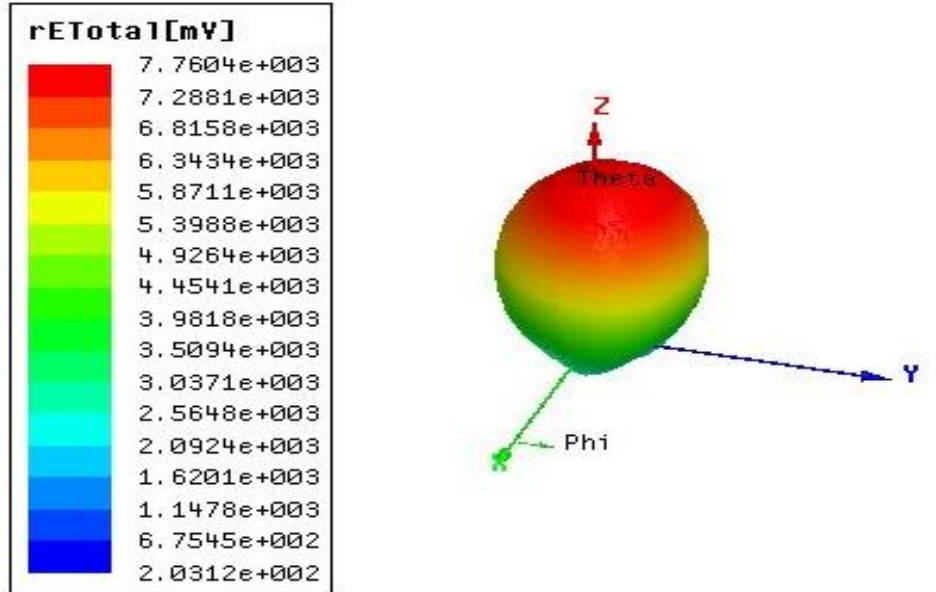

Figure 11 3D Radiation pattern of two radiating patch MIMO antenna

\section{DESIGN OF FOUR RADIATING PATCH MIMO ANTENNA}

The four radiating patch MIMO antenna is designed by placing the four elements orthogonal to each other which is the polarization diversity [10] to reduce the mutual coupling between the four radiating patches. The isolation between the elements are provided by placing the $\mathrm{L}$ shaped metallic structure between the elements. To provide more[11] isolation the Slotted Ground Plane is used in which the slots are etched on the ground plane. The proposed four radiating patch MIMO antenna is shown in the figure.12. The Slotted Ground Plane is shown in the figure.13.

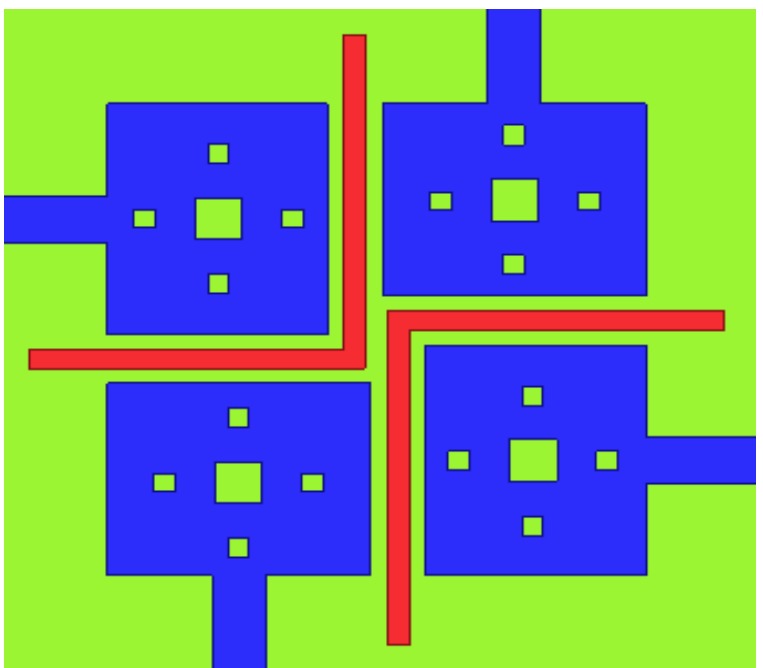

Figure 12 Geometry of four radiating patch MIMO antenna 
Vol. 8, Issue 5, May 2019

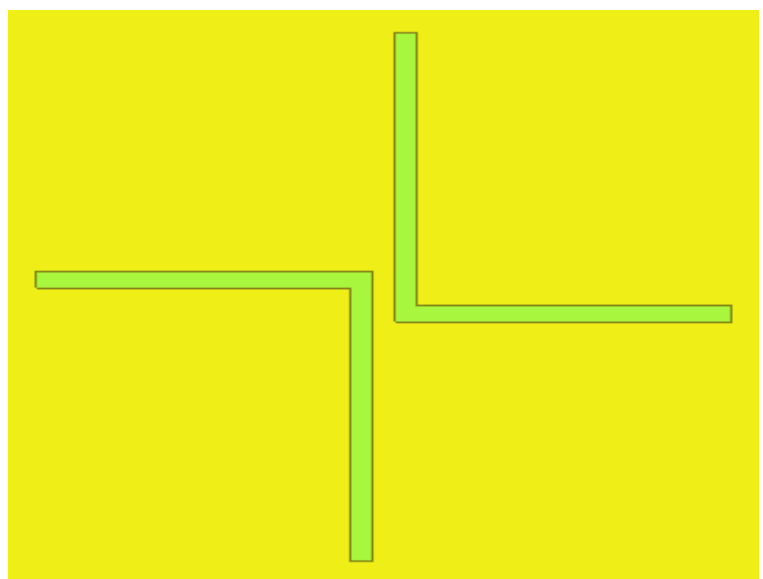

Figure 13 SGP of four radiating patch MIMO antenna

The gain of the four radiating patch MIMO antenna is $2.3 \mathrm{~dB}$ which is shown in the figure.14. The directivity of four radiating patch MIMO antenna is $3.5 \mathrm{~dB}$ which is shown in the figure. 15 .
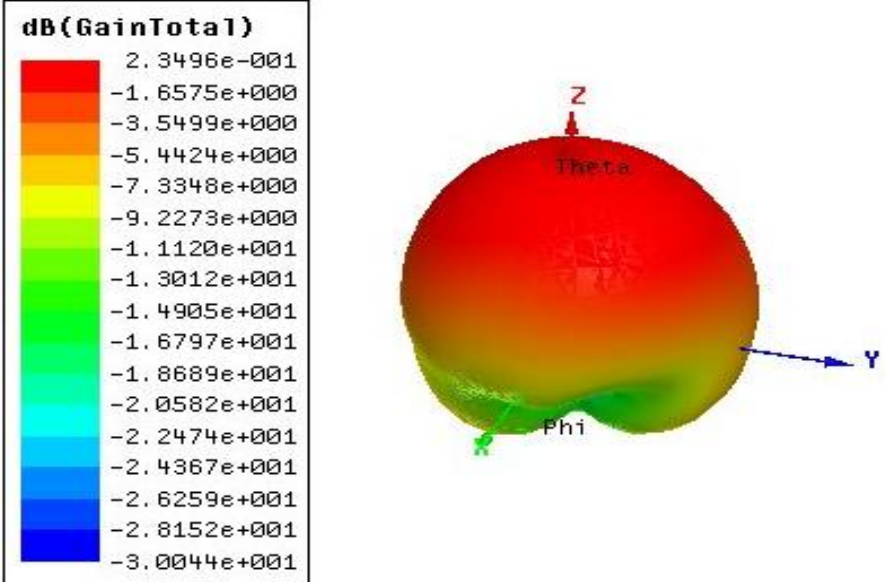

Figure 14 Gain of four element MIMO antenna
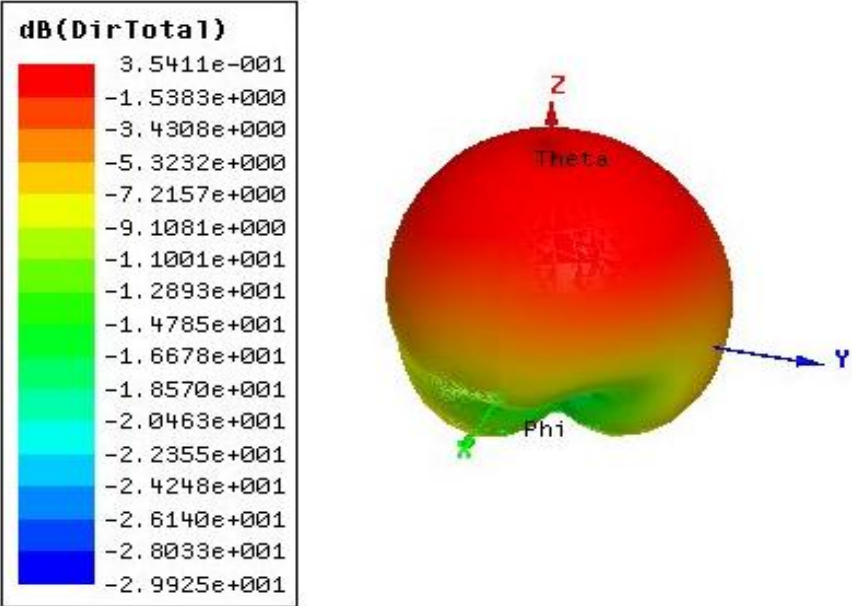

Figure 15 Directivity of four element MIMO antenna

The four radiating patch MIMO antenna has four ports and its return losses are $\mathrm{S}_{11}, \mathrm{~S}_{22}, \mathrm{~S}_{33}, \mathrm{~S}_{44}$ with $-4.5 \mathrm{~dB},-4.8 \mathrm{~dB}$, $4.9 \mathrm{~dB},-5.4 \mathrm{~dB}$ at $2.6 \mathrm{GHz}$ and $-15.2 \mathrm{~dB},-15.5 \mathrm{~dB},-16.7 \mathrm{~dB},-17 \mathrm{~dB}$ at $4.2 \mathrm{GHz}$ which are shown in the figure.16, 17, 18 and 19. When the power[12] is not delivered to the load there will be the return of power called return loss. The scattering matrix element corresponds to the losses associated with the design structure. 
International Journal of Advanced Research in Computer and Communication Engineering

Vol. 8, Issue 5, May 2019

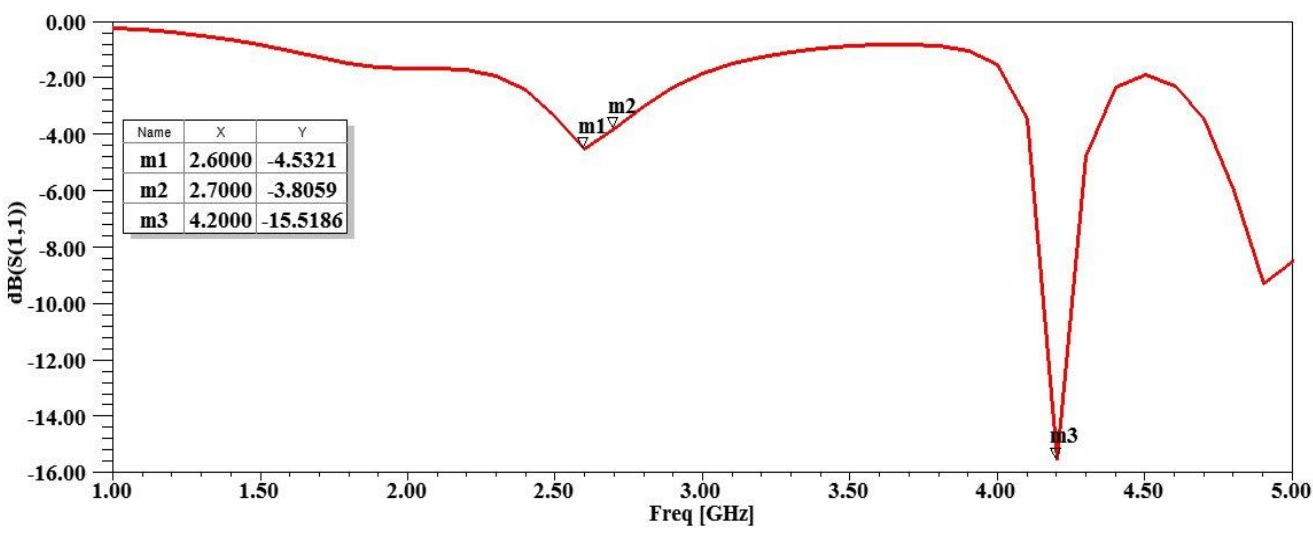

Figure $16 \mathrm{~S}_{11}$ of four radiating patch MIMO antenna

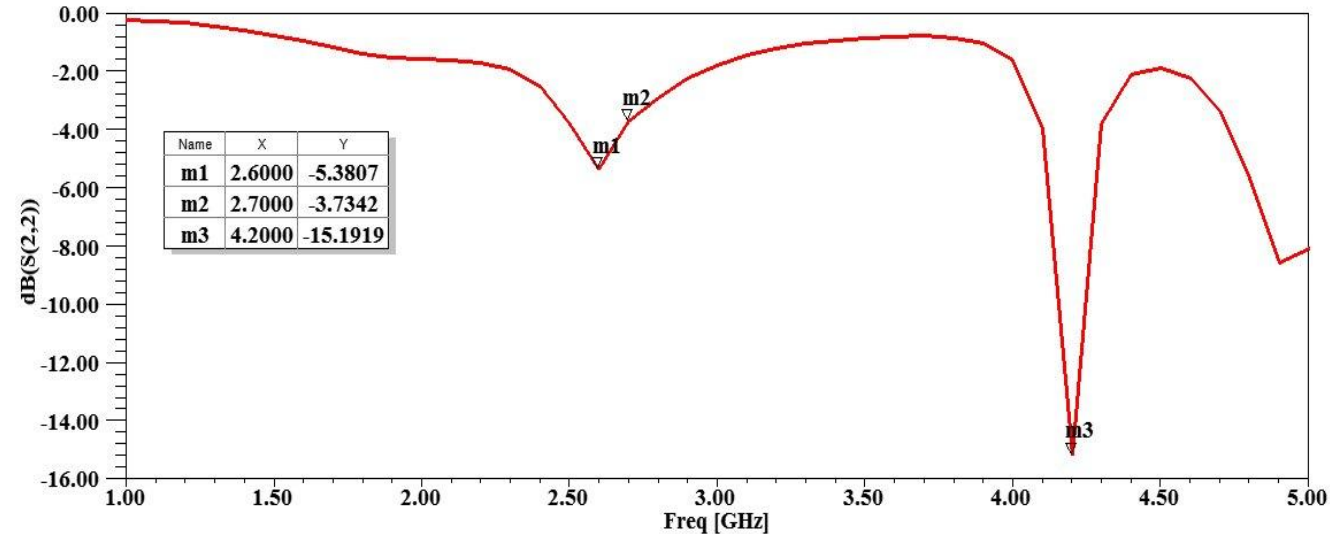

Figure $17 \mathrm{~S}_{22}$ of four radiating patch MIMO antenna

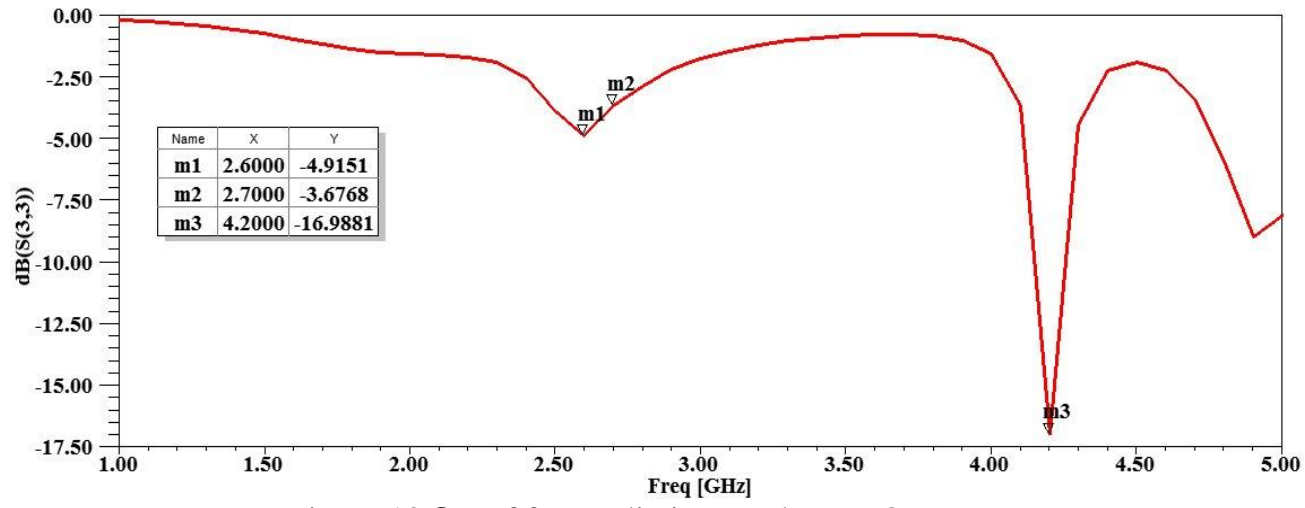

Figure $18 \mathrm{~S}_{33}$ of four radiating patch MIMO antenna

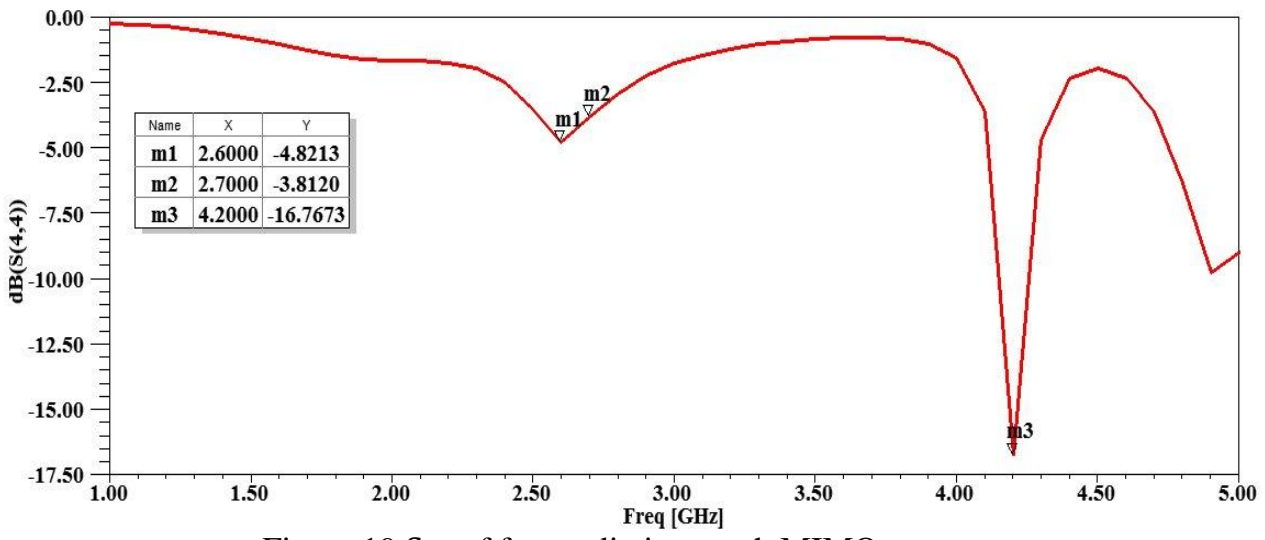

Figure $19 \mathrm{~S}_{44}$ of four radiating patch MIMO antenna 


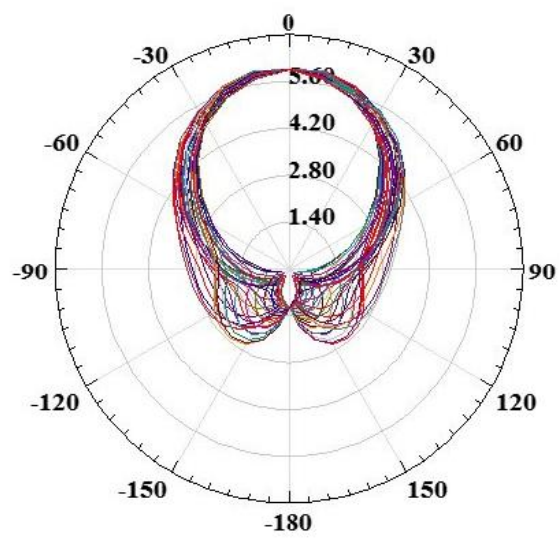

Figure 20 2D Radiation pattern of four radiating patch MIMO antenna

From the figure. 20 it is observed that the four radiating patch MIMO antenna has some side lobes compared to the two radiating patch MIMO antenna. As the microstrip patch is used in this proposed MIMO antenna the fringing $\mathrm{E}-$ fields on the edge of the microstrip antenna add up in plane and produce the radiation of the microstrip patch antenna as shown in the figure. 21 .
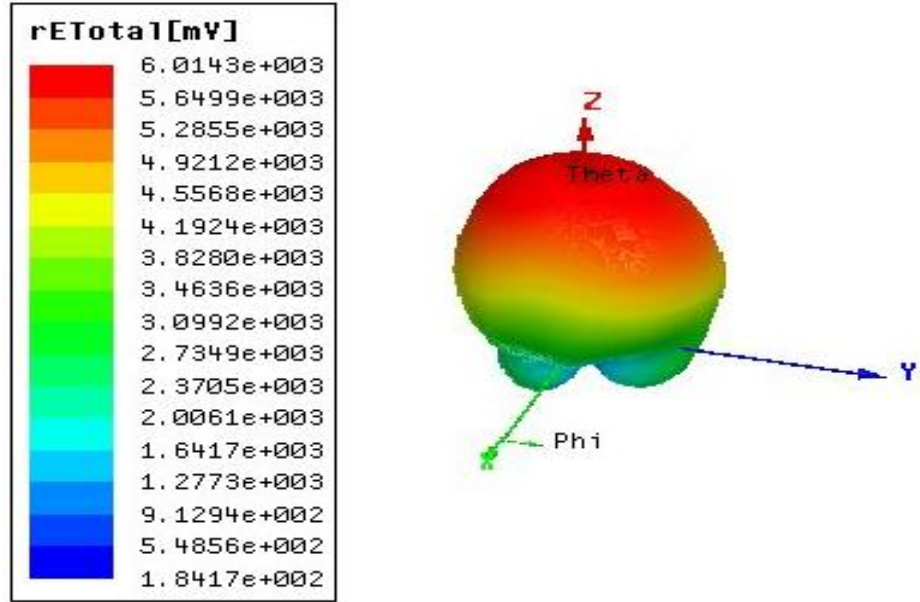

Figure 21 3D Radiation pattern of four radiating patch MIMO antenna

\section{CONCLUSION}

This paper presents the planar MIMO antenna which is composed of four radiating microstrip patches. The four radiating patches are separated by metallic structure and the isolation is achieved by the Slotted Ground Plane. Mutual coupling between the patches are reduced by having the polarization diversity which is achieved by placing the patches orthogonal to each other on the substrate. It is designed and simulated in HFSS. This antenna has multiple frequencies such as $2.6 \mathrm{GHz}$ and $4.2 \mathrm{GHz}$. The proposed antenna posses the gain and directivity of about $2.34 \mathrm{~dB}$ and $3.5 \mathrm{~dB}$ with the return loss of about $-5.4 \mathrm{~dB}$. In future this can be extended by using arrays and the performance can be analyzed with various substrates and isolation techniques.

\section{REFERENCES}

[1]. Jandi, Y., F. Gharnati, and A. O. Said, "Design of a compact dual bands patch antenna for 5G applications," 2017 International Conference on Wireless Technologies, Embedded and Intelligent Systems (WITS), 1-4, IEEE, April 2017.

[2]. Anil Kumar, B.Murugeshwari, S.Raghavan, "Design of Substrate Integrated Waveguide Power Divider \& Parameter optimization using Neural Network", IOSR Journal of Electronics \& Communication Engg, (IOSR-JECE), Vol.13, issue 1, Ver. I (Jan.- Feb. 2018), PP 37-43

[3]. R.Samson Daniel, "Design and Simulation of Multiband CPW feed Ring Shaped Antenna for Wireless Applications" International Journal of Engineering Sciences \& Research Technology, pp.549-553, 2014.

[4]. NagarajHanchinamani, Dr.C.R. Byrareddy, “A Survey of Microstrip Patch Antenna for MIMO” International Journal of Innovative Research in Computer and Communication Engineering,Vol-3, Issue-12, Dec 2015.

[5]. R Samson Daniel, R Pandeeswari, S Raghavan "Dual-band monopole antenna loaded with ELC metamaterial resonator for WiMAX and WLAN applications" Applied Physics A, vol.124, issue18,2018

[6]. N. ThamilSelvi, R. Pandeeswari, and P. N. ThiruvalarSelvan, An Inset-Fed Rectangular Microstrip Patch Antenna with Multiple Split Ring Resonator Loading for WLAN and RF-ID Applications, PIER C, vol.81, pp.41 - 52, 2018. 
[7]. N. ThamilSelvi, P. N. ThiruvalarSelvan, S. P. K. Babu, R. Pandeeswari, and R. Samson Daniel, "A Broad-Side Coupled SRR Inspired CPW Fed Dual Band Antenna for WiMAX and Wave Applications", PIER C vol. 80, pp.221 -231, 2018.

[8]. S.Monisha, U.Surendar, "A Survey on Wearable Antenna for ISM Band Application", IOSR Journal of Electronics and Communication Engineering, pp. 49-54, 2018.

[9]. S.Praveena, B.Murugeshwari, U.Surendar R. Kayalvizhi “A Review on Antenna Design for Millimeter Wave range”, IOSR Journal of Electronics and Communication Engineering, pp. 01-06, 2018.

[10]. Gayathri R, Maheswari M, "Design And Fabrication Of Dual Band RFID Antenna Using Hybrid Coupler With CSRR", Pakistan Journal of Bio Technology, Vol.14(1), pp. 87-89, 2017.

[11]. Varikuntla Krushnakanth, B.Murugeshwari \& SingaraveluRaghavan, "Design of a CPW Fed Substrate integrated waveguide using Frequency selective surface" $11^{\text {th }}$ International Radar symposium India( IRSI'17), Bangalore, India.

[12]. Muruganantham T, Surendar U, Balakumar "ADual Band Bandpass Filter With Sharp Passband Resonances Using Dual-Mode SIRs" International journal of microwave applications, volume 6, no.2,March-April 2017.

\section{BIOGRAPHIES}

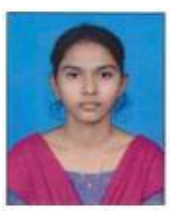

D.Stephy Angel working as Assistant Professor of Department of ECE in K.Ramakrishnan College of Engineering, Trichy, India. She completed her B.E and M.E(Communication Systems) in department of ECE at K.Ramakrishnan College of Engineering, Trichy, India. Her research interests are Antennas, Electromagnetic Fields, Transmission Lines, RF and Microwave Engineering.

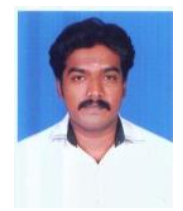

N.R.Nagarajan working as Assistant Professor of Department of ECE in K.Ramakrishnan College of Engineering, Trichy, India. He completed his B.E in Pavendar Bharathidasan college of Engineering and Technology, India and M.E(VLSI Design) in department of ECE at Kings College of Engineering, India. His research interests are 5G Standards and Implementation, Space Time Communication, Millimeter Wave Communication.

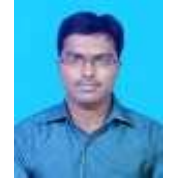

U.Surendar, completed Bachelors degree in Electronics and Communication Engineering and Masters in Communication Systems from Anna University in 2011 and 2014 respectively. He is lifetime Member of Indian Society of Technical Education (MISTE), and field of research interest is designing RF antennas and filters for advanced wireless mobile applications. Presently working as Assistant Professor, ECE Dept. in K. Ramakrishnan College of Engineering, Trichy, currently pursuing Ph.D. 